\title{
Delirium and Length of Hospital Stay among Medical Inpatients in Jos University Teaching Hospital, North-Central Nigeria
}

\author{
Maigari Yusufu Taru1,2*, Lubuola Issa Bamidele², Akinyemi Opeyemi Faith², \\ Gyang Bwatyum Annah², Okonoda Kingsley Mayowa',2, Aishatu Armiya'u Yushau² \\ ${ }^{1}$ Department of Psychiatry, University of Jos, Jos, Nigeria \\ ${ }^{2}$ Department of Psychiatry, Jos University Teaching Hospital, Jos, Nigeria \\ Email: *Tmaigariyusufu@yahoo.com
}

How to cite this paper: Taru, M.Y., Bamidele, L.I., Faith, A.O., Annah, G.B., Mayowa, O.K. and Yushau, A.A. (2018) Delirium and Length of Hospital Stay among Medical Inpatients in Jos University Teaching Hospital, North-Central Nigeria. Open Journal of Psychiatry, 8, 297-314.

https://doi.org/10.4236/ojpsych.2018.83024

Received: June 22, 2018

Accepted: July 27, 2018

Published: July 30, 2018

Copyright $\odot 2018$ by authors and Scientific Research Publishing Inc. This work is licensed under the Creative Commons Attribution International License (CC BY 4.0).

http://creativecommons.org/licenses/by/4.0/

\begin{abstract}
Delirium is a complex neuropsychiatric syndrome that is often associated with adverse outcomes including prolonged hospitalization. This study aims to determine the length of hospital stay among medically-ill patients with and without delirium who were admitted through the Accident and Emergency unit of the Jos University Teaching Hospital, in North-Central Nigeria. It was a cross-sectional study that employed a consecutive sampling technique to select 290 eligible subjects in a face-to-face interview, using a confusion assessment method to assess for delirium within 24 hours of admission. All the respondents were followed-up from the Accident and Emergency unit until discharge or death. The results showed that respondents with delirium rather than those without, were significantly more likely to stay longer in the hospital $(\mathrm{P}<0.001)$. The significant factors associated with prolonged hospitalization among those with delirium include, current medications use, duration of illness before presentation and type of medical diagnosis $(\mathrm{P}<0.001),(\mathrm{P}<$ $0.001)$ and $(\mathrm{P}<0.001)$ respectively. The results point to the importance of screening for delirium in medically-ill patients, with particular attention to patients with infectious and cerebrovascular diseases.
\end{abstract}

\section{Keywords}

Delirium, Medical Inpatients, Accident and Emergency, Length of Stay

\section{Introduction}

The term delirium was originally derived from a Latin word Delirare which 
means to be "off the track" or "to go wrong" [1]. Since then, the condition has witnessed various descriptions that in the late $19^{\text {th }}$ century, it was first viewed as a stable psychiatric diagnosis [2]. In the early $20^{\text {th }}$ century, the concepts of underlying brain pathology, cognitive impairment and other new ideas introduced by Karl Jasper and other authorities in the field of mental health created a platform for another successive transformation [3]. This created the platform where delirium witnessed other transformations; from a functional disorder to psychosis, from psychosis to non-specific brain reaction and exogenous irritant respectively [4].

Delirium was officially included in the Diagnostic and Statistical Manual of Mental disorders, third edition (DSM III) classification in late $20^{\text {th }}$ century [5]. The definition of delirium has continuously been modified in subsequent editions, with DSM- 5 being the current one. Based on DSM- 5 definition, delirium is an acute onset of fluctuating cognitive impairment and a disturbance of consciousness which is characterized by disturbances of orientation, memory, language skills, thinking, perception, motor behaviour, sleep wake cycle and with impaired attention as the core cognitive disturbance that is not better explained by pre-existing, established or other evolving neurocognitive disorders [6].

Delirium is very common among hospitalized adults in low, middle and high income countries, with prevalence, ranging between $8.3 \%$ in the United States of America (USA) [7] and 32\% in Nigeria [8].

This condition is often associated with adverse clinical outcomes, including but not limited to increased mortality, accelerated cognitive decline, Length of Stay (LOS) in the hospital. Previous hospital-based studies have investigated the negative effects of delirium on clinical outcomes. From these studies, delirium has been associated with prolonged hospitalization [9]-[14], and this has been shown to be independent of baseline patient's characteristics and aetiological factors [15]. Moreover, it has been documented that hospitalized patients with delirium are more prone to developing urinary incontinence, decubitus ulcers, and malnutrition [16] [17]. This can then lead to prolonged hospital stays, with consequent greater financial and economic burden on the patient and careers [17] [18].

Most of what is known about delirium and length of hospital stay is from studies performed in western countries [9] [10] [11] [19]. Such studies are scarce in Sub-Saharan Africa and indeed Nigeria.

The aim of this study was to assess the length of hospital stay in medically-ill adults admitted through the Accident and Emergency (A \& E) unit of the Jos University Teaching Hospital (JUTH), North-Central Nigeria and to identify if any, the socio-demographic and clinical characteristics associated with length of hospital stay among respondents with delirium.

\section{Methodology}

\subsection{Participants and Procedure}

A cross-sectional study that was designed to compare the length of hospital stay 
among medical inpatients with and without delirium in North Central Nigeria. The study was conducted between July 2016 and March 2017 at the A \& E unit of the Jos University Teaching Hospital, which is located at the outskirts of Jos metropolis. The hospital provides specialist medical services for North-Central States and few States from North-East and North Western Nigeria.

The A \& E unit of the hospital runs for 24 hours daily and has an average attendance of 100 medically-ill patients per week. The medical wards have a total of 100 bed space, with average inpatient admission duration of 4 weeks, depending on the medical condition.

Ethical approval was obtained from the Ethical Committee of the Jos University Teaching Hospital, while permission was granted by the heads of A \& E unit and Internal medicine.

Medically-ill adults aged 18 years and above who were admitted through A \& E unit of JUTH, gave consent either by themselves or through their relatives to participate in the study. Medically ill patients considered too ill to participate in the study were excluded.

In this study, medical inpatients refer to those being managed under the medical team and were selected based on a wide range of conditions they presented with.

The minimum sample size was calculated using Kish [20] formula for cross sectional studies based on a prior estimate of $17.53 \%$ for delirium [21]. Sample size of 300 was calculated.

The study employed a consecutive sampling of the respondents aged 18 years and above who presented within 24 hours to A \& E unit of the hospital.

Data were collected by trained researchers and research assistants who are fluent in both English and Hausa languages, from consecutive patients in their private cubicles ensuring that they had enough privacy. Information was obtained from relatives of patients who were too confused to give informed consent, as recommended in other studies on capacity and consent in delirium research [22] [23]. It was made clear to all the respondents that the interviews were entirely voluntary and that they could withdraw from the research at any stage without negative implications on their treatments.

\subsection{Materials}

Demographic variables were assessed using a Sociodemographic Questionnaire. This sought information on socio-demographic data (age, gender, level of education, marital status, occupation, individual monthly income, religion and ethnicity).

This questionnaire also included information on clinical characteristics such as current medication, past year substance use, mental illness history, prior cognitive impairment, physical impairment, illness duration before presentation and medical diagnosis.

Richmond Agitation Sedation Scale (RASS) was first used to assess patient's response to verbal or physical stimulation. It is scaled from -5 to +4 . Only those 
who scored -3 and above were administered the Confusion assessment method (CAM) to assess for delirium. Confusion Assessment Method tool is the most commonly used and validated delirium detection tool. It can be administered in less than 5 minutes and closely correlates with DSM-5 criteria for delirium. These instruments (RASS and CAM) have been used in Nigeria [24].

Confusion Assessment Method evaluates the four key delirium features:

1) Acute onset and fluctuating course.

2) Inattention.

3) Disorganized thinking and

4) Altered level of consciousness.

Delirium is considered present if features (1) and (2) were present in addition to either features (3) or (4).

All the respondents (both delirious and non-delirious groups) were followed-up from A\&E admission to medical wards, in order to determine their LOS, which was calculated by subtracting the date of A \& E admission from the date of hospital discharge or death. In this study, respondents who were discharged or died within two weeks of hospital admission were considered as having shorter length of hospital stay while those who were discharged or died after 2 weeks were considered as having longer length of hospital stay

\subsection{Data Analysis}

The Statistical Package for Social Sciences version 20 (SPSS-20) Software package was used to analyze the data. The results were presented using simple descriptive analysis. T-test was used to compare mean values of numerical variables and chi-square test was used to investigate the difference between categorical variables and their associations. Values of $\mathrm{P}<0.05$ were considered statistically significant.

\section{Results}

A total of 302 respondents were interviewed, but 290 (96\%) interviews comprising 104 (35.9\%) with delirium and 186 (64.1\%) without delirium were used in the analysis. The remaining 12 were excluded because of incomplete data. In addition, mortality was recorded in $18(17.3 \%)$ of the 104 respondents with Delirium as well as $22(11.8 \%)$ of the 186 without Delirium respectively.

Table 1 summarizes the sociodemographic characteristics of respondents with and without delirium. More than $80 \%$ of all respondents were below 65 years. However, the mean age of the respondents differed significantly, with those with delirium (52.2 \pm 18.4 years) being older than those without delirium (42.8 \pm 15.6 years) $(\mathrm{P}=0.001)$. The sample comprised of a significantly higher proportion of males, 59 (46.8\%) than females, $45(27.4 \%)$ who had delirium $(\mathrm{P}<0.001)$. Both groups also differed significantly with respect to their employment status and income levels with those without delirium being more likely to be unemployed $(\mathrm{P}<0.001)$ and had irregular individual monthly income of less than $\mathrm{N} 20,000(\mathrm{P}<$ 
0.001). More than half of the respondents with; 67 (64.4) and without; 98 (52.7) delirium were married, 59 (83.1\%) of the 71 respondents who were never married had delirium and the rest were either previously married (divorced/separated); 7 (2.4\%) or widowed; 47 (16.2\%). The two groups differed significantly with respondents without delirium being more likely to have been never married $(P=0.001)$. The two groups did not differ significantly with respect to ethnicity $(\mathrm{P}=0.230)$, religion $(\mathrm{P}=0.241$ and educational status $(\mathrm{P}=$ $0.239)$.

Table 2 summarizes the Clinical characteristics of respondents with and without delirium. This shows that 216 (79\%) of the 290 respondents did not use substance for the past one year. Among current or past year substance users, alcohol was the most frequently used substance in respondents with $24(23.1 \%)$ and without delirium 35 (18.8\%). All the 10 respondents with multiple substance use except $1(10 \%)$ were diagnosed with delirium. The two groups differed significantly with those with delirium being more likely to use multiple substances $(\mathrm{P}=0.002)$. While $30 \%$ of the 179 respondents without prior cognitive impairment had delirium, a significantly high proportion of the respondents with Prior cognitive impairment; 27/34 (79.4\%) were diagnosed with delirium ( $\mathrm{P} \leq 0.001$ ). The most frequent medical condition among respondents was infectious diseases; 140 (48.3\%). Other relatively common medical conditions were major organ failures; 52 (17.9\%) and other medical conditions not specified; 41 (14.1\%). The two groups differed significantly, with respondents diagnosed with infectious diseases being less likely to have delirium $(P=0.001)$. There were no other between-group differences with respect to clinical characteristics of the respondents.

Table 3 shows the comparison of respondents with and without delirium based on length of stay in the hospital. While 71 (68.3\%) of the 104 respondents with delirium had longer length of hospital stay ( $\geq 14$ days), similar length of hospital stay ( $\geq 14$ days) was observed in 72 (38.7\%) of the 186 respondents without delirium. The comparison of the two groups based on hospital length of stay showed that those with delirium rather than those without were significantly more likely to stay longer in the hospital $(\mathrm{P}<0.001)$.

Table 4 summarizes the association between length of stay in the hospital and Sociodemographic characteristics of respondents with delirium. Across all age groups, majority of the respondents with delirium compared to those without had a longer duration of hospital stay. However, there was no statistically significant association between length of hospital stay and age $(P=0.134)$. Though more than two-third of both males; 41 (69.5\%) and females; 30 (66.7\%) with delirium stayed for at least 2 weeks in the hospital, there was no statistically significant gender difference in length of hospital stay $(P=0.759)$. In the same manner, there was no statistically significant influence of ethnicity $(P=0.294)$, religion $(P=0.767)$, level of education $(P=0.822)$ and other sociodemographic factors on length of hospital stay. 
Table 5 summarizes the Association between length of stay in the hospital and Clinical Characteristics of respondents with delirium. Among the 104 respondents diagnosed with delirium, 20 (71.4\%) of the 28 respondents on regular antibiotics and $17(60.7 \%)$ of the 28 respondents on antihypertensive had shorter length of hospital stays ( $\leq 14$ days). In contrast, a higher proportion of respondents on antikocks; 7/8 (87.5\%), hypoglycaemics; 7/11 (63.6\%) and other medications not specified; $16 / 29$ (55.2\%), stayed longer in the hospital. The difference was statistically significant, with those on antikocks or hypoglycaemics being more likely to stay longer in the hospital $(P=0.035)$. Similarly, $(55 \%)$ of the 33 respondents who presented within 2 weeks of their illnesses' duration had a shorter length of hospital stay as against a higher proportion of those who presented at $\geq 2$ weeks of illness duration, whose length of hospital stay was significantly increased $(P=0.007)$. In the same way, a comparison of length of hospital stay among patients with delirium based on medical diagnosis revealed that respondents with either infectious or cardiovascular diseases were significantly more likely to stay longer in the hospital compared to those with other medical conditions $(P=0.017)$. There were no other significant association between length of hospital stay and other clinical characteristics of the respondents.

Table 1. Sociodemographic characteristics of respondents with and without delirium.

\begin{tabular}{|c|c|c|c|c|c|c|}
\hline \multirow[t]{2}{*}{ Variables } & \multicolumn{3}{|c|}{ Delirium } & \multicolumn{3}{|c|}{ Statistics } \\
\hline & Yes $=\mathbf{n}(\%)$ & No $=\mathrm{n}(\%)$ & $\begin{array}{c}\text { Total }=\mathrm{N} \\
(\%)\end{array}$ & $\mathrm{X}^{2}$ & df & $\mathbf{P}$ \\
\hline \multicolumn{7}{|l|}{ Age } \\
\hline $18-34$ & $29(27.9)$ & 89 (47.9) & $118(40.7$ & 30.924 & 2 & $<0.001$ \\
\hline $35-64$ & $42(40.4)$ & $83(44.6)$ & $125(43.1)$ & & & \\
\hline $65-100$ & $33(31.7)$ & $14(7.5)$ & $47(16.2)$ & & & \\
\hline Mean age $\pm S D$ & $52.2 \pm 18.4$ & $42.8 \pm 15.6$ & & & & \\
\hline \multicolumn{7}{|l|}{ Gender } \\
\hline Male & $59(46.8)$ & $67(53.2)$ & $126(100)$ & 11.643 & 1 & 0.001 \\
\hline Female & $45(27.4)$ & $119(72.6$ & $164(100)$ & & & \\
\hline \multicolumn{7}{|l|}{ Ethnicity } \\
\hline Berom & $23(22.1)$ & $37(19.9)$ & $60(20.7)$ & 2.943 & 2 & 0.230 \\
\hline Hausa/Fulani & $8(7.7)$ & $27(14.5)$ & $35(12.1)$ & & & \\
\hline Others & $73(70.2)$ & $122(65.6)$ & $195(67.2)$ & & & \\
\hline \multicolumn{7}{|l|}{ Religion } \\
\hline Christianity & $91(37.3)$ & $153(62.7)$ & $244(100)$ & 1.373 & 1 & 0.241 \\
\hline Islam & $13(28.3)$ & $33(71.7)$ & $46(100)$ & & & \\
\hline \multicolumn{7}{|l|}{ Educational status } \\
\hline No formal education & $12(11.5)$ & $10(5.4)$ & $22(7.6)$ & 4.219 & 3 & 0.239 \\
\hline Primary education & $35(33.7)$ & $59(31.7)$ & $94(32.4)$ & & & \\
\hline
\end{tabular}




\section{Continued}

\begin{tabular}{ccccccc}
\hline Secondary education & $31(29.8)$ & $61(32.8)$ & $92(31.7)$ & & & \\
Tertiary education & $26(25.0)$ & $56(30.1)$ & $82(28.3)$ & & \\
Occupational status & & & & & & \\
Professionals \pm degree & $30(28.8)$ & $40(21.5)$ & $70(24.1)$ & 16.850 & 2 & $<0.001$ \\
Non professionals & $55(52.9)$ & $68(36.6)$ & $123(42.4)$ & & & \\
Unemployed & $19(18.3)$ & $78(41.9)$ & $97(33.4)$ & & & \\
Estimated income/month & & & & & & \\
$<20,000.00$ & $39(37.5)$ & $111(59.7)$ & $150(51.7)$ & 15.711 & 2 & $<0.001$ \\
$20,000.00-49,000.00$ & $52(50.0)$ & $67(36.0)$ & $119(41.0)$ & & & \\
$\geq 50,000.00$ & $13(12.5)$ & $8(4.3)$ & $21(7.2)$ & & & \\
Marital status & & & & & & \\
Never married & $12(11,5)$ & $59(31.7)$ & $71(24.5)$ & 15.679 & 3 & 0.001 \\
Married & $67(64.4)$ & $98(52.7)$ & $165(56.9)$ & & & \\
Previously married & $4(3.8)$ & $3(1.6)$ & $7(2.4)$ & & & \\
Widowed & $21(20.2)$ & $26(14.0)$ & $47(16.2)$ & & & \\
\hline
\end{tabular}

Table 2. Clinical characteristics of respondents with and without delirium.

\begin{tabular}{|c|c|c|c|c|c|c|}
\hline Response & $\begin{array}{c}\text { Yes }=\mathrm{n} \\
(\%)\end{array}$ & No $=n(\%)$ & $\begin{array}{c}\text { Total }=\mathrm{N} \\
(\%)\end{array}$ & $\mathrm{X}^{2}$ & Df & $\mathbf{P}$ \\
\hline \multicolumn{7}{|l|}{ Current medication } \\
\hline Regular antibiotics & $28(26.9)$ & $61(32.8)$ & $89(30.7)$ & 27.169 & 4 & 0.066 \\
\hline Anti-kock's & $28(26.9)$ & $26(14.0)$ & $54(18.6)$ & & & \\
\hline Oral hypoglycemic/insulin & $11(10.6)$ & $16(8.6)$ & $27(9.3)$ & & & \\
\hline Antihypertensive & $8(7.7)$ & $23(12.4)$ & $31(10.7)$ & & & \\
\hline Others & $29(27.9)$ & $60(57.1)$ & $89(30.7)$ & & & \\
\hline \multicolumn{7}{|l|}{ Past-year substance use/type } \\
\hline Abstinence & $69(66.3)$ & $147(79.0)$ & $216(74.5)$ & 14.816 & 3 & 0.002 \\
\hline Alcohol & $24(23.1)$ & $35(18.8)$ & $59(20.3)$ & & & \\
\hline Multiple (alcohol, tramadol, BDZ) & $9(8.7)$ & $1(0.5)$ & $10(3.4)$ & & & \\
\hline Others & $2(1.9)$ & $3(1.6)$ & $5(1.7)$ & & & \\
\hline \multicolumn{7}{|l|}{ Mental illness history } \\
\hline Yes & $5(35.7)$ & $9(64.3)$ & $14(100)$ & 0.000 & 1 & 0.991 \\
\hline No & $99(35.9)$ & $177(64.1)$ & $276(100)$ & & & \\
\hline \multicolumn{7}{|l|}{ Prior cognitive impairment } \\
\hline Yes & $27(79.4)$ & $7(20.6)$ & $34(100)$ & 29.831 & 1 & $<0.001$ \\
\hline No & $77(30.1)$ & $179(69.9)$ & $256(100)$ & & & \\
\hline \multicolumn{7}{|l|}{ Physical impairment } \\
\hline Yes & $7(29.2)$ & $17(70.8)$ & $24(100)$ & 0.510 & 1 & 0.475 \\
\hline
\end{tabular}




\section{Continued}

\begin{tabular}{ccccccc}
\hline No & $97(36.5)$ & $169(63.5)$ & $266(100)$ & & \\
Illness duration before presentation & & & & & & \\
$<2$ weeks & $27(26.0)$ & $45(24.2)$ & $72(24.8)$ & 0.172 & 2 & 0.918 \\
$2-4$ weeks & $64(61.5)$ & $119(64.0)$ & $183(63.1)$ & & & \\
$>4$ weeks & $13(12.5)$ & $22(11.8)$ & $35(12.1)$ & & & \\
Medical diagnosis & & & & & & \\
Infectious diseases & $42(40.4)$ & $98(52.7)$ & $140(48.3)$ & 18.787 & 4 & 0.001 \\
Organ failures (CLD, CKD \& HHD) & $30(28.8)$ & $22(11.8)$ & $52(17.9)$ & & & \\
Cerebrovascular disease (stroke) & $11(10.6)$ & $17(9.1)$ & $28(9.7)$ & & & \\
Poor glycemic control & $13(12.5)$ & $16(8.6)$ & $29(10.0)$ & & & \\
Others & $8(7.7)$ & $33(17.7)$ & $41(14.1)$ & & \\
\hline
\end{tabular}

Table 3. Comparison of respondents with and without delirium based on length of stay in the hospital.

\begin{tabular}{ccccccc}
\hline Delirium & \multicolumn{3}{c}{ Length of stay } & \multicolumn{3}{c}{ Statistics } \\
& $<2$ weeks & $\geq 2$ weeks & Total & $\mathbf{X}^{2}$ & Df & P \\
Yes & $33(31.7 \%)$ & $71(68.3 \%))$ & $104(100 \%)$ & 23.318 & 1 & $<0.001$ \\
No & $114(61.3 \%)$ & $72(38.7 \%)$ & $186(100 \%)$ & & & \\
Total & $147(50.7 \%)$ & $143(49.3 \%)$ & $290(100 \%)$ & & & \\
\hline
\end{tabular}

Table 4. Association between length of stay in the hospital and Sociodemographic characteristics of respondents with delirium.

\begin{tabular}{|c|c|c|c|c|c|c|}
\hline \multirow[t]{2}{*}{ Variables } & \multicolumn{3}{|c|}{ Length of stay in days } & \multicolumn{3}{|c|}{ Statistics } \\
\hline & $5-13$ & $14-40$ & Total & $\mathbf{X}^{2}$ & df & $\mathbf{P}$ \\
\hline & n (\%) & n (\%) & $\mathrm{N}(\%)$ & & & \\
\hline \multicolumn{7}{|l|}{ Age } \\
\hline $18-34$ & $5(15.2)$ & $24(33.8)$ & $29(27.9)$ & 4.012 & 2 & 0.134 \\
\hline $35-64$ & $15(45.5)$ & $27(38.0)$ & $42(40.4)$ & & & \\
\hline $65-100$ & $13(39.4)$ & $20(28.2)$ & $33(31.7)$ & & & \\
\hline \multicolumn{7}{|l|}{ Gender } \\
\hline Male & $18(30.5)$ & $41(69.5)$ & $59(100)$ & 0.094 & 1 & 0.759 \\
\hline Female & $15(33.3)$ & $30(66.7)$ & $45(100)$ & & & \\
\hline \multicolumn{7}{|l|}{ Ethnicity } \\
\hline Berom & $9(27.3)$ & $14(19.7)$ & $23(22.1)$ & 2.447 & 2 & 0.294 \\
\hline Hausa /Fulani & $4(12.1)$ & $4(5.5)$ & $8(7.7)$ & & & \\
\hline Others & $20(60.6)$ & $53(74.6)$ & $73(70.2)$ & & & \\
\hline Religion & & & & & & \\
\hline
\end{tabular}




\section{Continued}

\begin{tabular}{|c|c|c|c|c|c|c|}
\hline Christianity & $27(29.7)$ & $64(70.3)$ & $91(100)$ & 1.427 & 1 & $0.767^{\star}$ \\
\hline Islam & $6(46.2)$ & $7(53.8)$ & $13(100)$ & & & \\
\hline \multicolumn{7}{|l|}{ Educational status } \\
\hline No formal education & $5(15.2)$ & $7(9.9)$ & $12(11.5)$ & 0.912 & 3 & 0.822 \\
\hline Primary education & $10(30.3)$ & $25(35.2)$ & $35(33.7)$ & & & \\
\hline Secondary education & $9(27.3)$ & $22(31.0)$ & $31(29.8)$ & & & \\
\hline Tertiary education & $9(27.3)$ & $17(23.9)$ & $26(25.0)$ & & & \\
\hline \multicolumn{7}{|l|}{ Occupational status } \\
\hline Professionals \pm degree & $12(36.4)$ & $18(25.4)$ & $30(28.8)$ & 1.964 & 2 & 0.375 \\
\hline Non professionals & $17(51.5)$ & $38(53.5)$ & $55(52.9)$ & & & \\
\hline Unemployed & $4(12.1)$ & $15(21.1)$ & $19(18.3)$ & & & \\
\hline \multicolumn{7}{|l|}{ Estimated income/month } \\
\hline$<20,000.00$ & $10(30.3)$ & $29(40.8)$ & $39(37.5)$ & 1.938 & 2 & 0.379 \\
\hline $20,000.00-49,000.00$ & $17(51.5)$ & $35(49.3)$ & $52(50.0)$ & & & \\
\hline$\geq 50,000.00$ & $6(18.2)$ & $7(9.9)$ & $13(12.5)$ & & & \\
\hline \multicolumn{7}{|l|}{ Marital status } \\
\hline Never married & $1(3.0)$ & $11(15.5)$ & $12(11.5)$ & 6.552 & 3 & 0.088 \\
\hline Married & $22(66.7)$ & $45(63.4)$ & $67(64.4)$ & & & \\
\hline Previously married & $3(9.1)$ & $1(1.4)$ & $4(3.8)$ & & & \\
\hline Widowed & $7(21.2)$ & $14(19.7)$ & $21(20.2)$ & & & \\
\hline
\end{tabular}

* = Yates correction.

Table 5. Association between length of stay in the hospital and Clinical Characteristics of respondents with delirium.

\begin{tabular}{|c|c|c|c|c|c|c|}
\hline \multirow[t]{2}{*}{ Variable } & \multicolumn{3}{|c|}{ Length of stay in days } & \multicolumn{3}{|c|}{ Statistics } \\
\hline & $5-13$ & $14-40$ & Total & $\mathrm{X}^{2}$ & Df & $\mathbf{P}$ \\
\hline & n (\%) & n (\%) & $\mathrm{N}(\%)$ & & & \\
\hline \multicolumn{7}{|l|}{ Current medication } \\
\hline Regular antibiotics & $20(27.3)$ & $8(26.8)$ & $28(26.9)$ & 10.34 & 4 & 0.035 \\
\hline Anti-kock's & $1(0.0)$ & $7(11.3)$ & $8(7.7)$ & & & \\
\hline Oral hypoglycaemic/insulin & $4(15.1)$ & $7(8.5)$ & $11(10.6)$ & & & \\
\hline Antihypertensive & $17(36.4)$ & $11(22.5)$ & $28(26.9)$ & & & \\
\hline Others & $13(21.2)$ & $16(30.9)$ & $29(27.9)$ & & & \\
\hline \multicolumn{7}{|l|}{ Past-year substance use/type } \\
\hline Abstinence & $24(34.8)$ & $45(63.4)$ & $69(66.3)$ & 1.482 & 3 & 0.686 \\
\hline Alcohol & $6(35.0)$ & $18(25.3))$ & $24(23.1)$ & & & \\
\hline Multiple & $1(50.0)$ & $1(1.4))$ & $2(1.9)$ & & & \\
\hline
\end{tabular}




\section{Continued}

\begin{tabular}{|c|c|c|c|c|c|c|}
\hline Others & $2(22.2)$ & $7(9.9)$ & $9(8.7)$ & & & \\
\hline \multicolumn{7}{|l|}{ Mental illness } \\
\hline Yes & $0(0.0)$ & $5(100)$ & $5(100)$ & - & - & - \\
\hline No & $33(33.3)$ & $66(66.7)$ & $99(100)$ & & & \\
\hline \multicolumn{7}{|l|}{ Prior-cognitive impairment } \\
\hline Yes & $8(30.8)$ & $18(69.2)$ & $26(100)$ & 0.015 & 1 & 0.903 \\
\hline No & $25(32.1)$ & $53(67.9)$ & $78(100)$ & & & \\
\hline \multicolumn{7}{|l|}{ Impairment } \\
\hline Yes & $3(28.6)$ & $4(71.4)$ & $7(100)$ & 0.414 & 1 & 0.840 \\
\hline No & $53(32.0)$ & $44(68.0)$ & $97(100)$ & & & \\
\hline \multicolumn{7}{|l|}{ Illness duration before presentation } \\
\hline$<2$ weeks & $15(45.4)$ & $12(16.9)$ & $27(26.0)$ & 10.017 & 2 & 0.007 \\
\hline 2 - 4 weeks & $16(48.5)$ & $48(67.6)$ & $64(61.5)$ & & & \\
\hline$>4$ weeks & $2(6.1)$ & $11(15.5)$ & $13(12.5)$ & & & \\
\hline \multicolumn{7}{|l|}{ Medical diagnoses } \\
\hline Infectious diseases & $8(33.3)$ & $34(43.7)$ & $42(40.4)$ & 12.055 & 4 & 0.017 \\
\hline Organ failures (CLD, CKD \& HHD) & $16(36.4)$ & $14(25.3)$ & $30(28.8)$ & & & \\
\hline Cerebrovascular disease & $2(3.0)$ & $9(14.1)$ & $11(10.6)$ & & & \\
\hline Poor glycemic control & $6(15.2)$ & $7(11.3)$ & $13(12.5)$ & & & \\
\hline Others & $4(12.1)$ & $4(5.6)$ & $8(7.7)$ & & & \\
\hline
\end{tabular}

* $=$ Yates correction.

\section{Discussion}

To our knowledge, this is the first hospital-based study to evaluate the relationship between delirium and length of hospital stay among medical inpatients in Nigeria.

Among the 290 medical inpatients interviewed, 104 (35.9\%) met the Confusion Assessment Method criteria for delirium. This is in keeping with findings from previous studies conducted in developed [7] [25] [26] and developing countries including Nigeria [8] [21]. In addition, respondents with and without delirium were found to differ with respect to gender, education, income and marital statuses, as well as Past-year substance use, Prior cognitive impairment and Medical diagnosis.

Notably, we found that respondents with delirium were more likely to stay longer in the hospital compared to those without. This agrees with results of previous studies conducted in the United States of America [9] [10], United Kingdom [11] [12], Portugal [13] and China [14], which all indicated that delirium was an independent risk factor for pronged length of hospital stay. However, there are sparse data on differential effects of delirium on clinical outcomes including length of hospital stay in Nigeria. Notwithstanding, the fact that this 
association has been demonstrated in countries believed to have better functioning health systems, suggests that prolonged length of hospital stay may also be a common occurrence in Nigeria.

The association between delirium and length of hospital stay may be due to several factors. For example, hospitalized patients with delirium are more prone to developing complications such as urinary incontinence, decubitus ulcers, nosocomial infections, malnutrition and self-injury from removal of catheter or falls [5] [16] [17]. These complications could further perpetuate the course of their illness, thus prolonging their length of stay in the hospital. Furthermore, poor adherence to treatment, especially in delirious patients with overt psychotic manifestations such as hallucinations and delusions [27] [28] may delay recovery, with consequent increased in length of hospital stay.

This study found that among the medical inpatients with delirium, having illness duration of at least two weeks before presentation to A and E unit was significantly associated with increased length of hospital stay. Though factors associated with late presentation were not assessed in this study, in most traditional communities in Nigeria; poor health seeking behaviour, erroneous belief that their health problems resulted from spiritual attack and lack of funds to seek proper health care are still the norms [29]. In addition, some of the patients in this study were referred from primary and secondary health facilities after several days to weeks of failed treatment. These combined factors could worsen the course of illness with consequent development of complications including delirium, which often require a longer length of inpatient treatment before symptoms can be resolved [11] [12] [13] [14].

Consistent with previous studies [30]-[36], which observed that chronic medical conditions such as stroke, Diabetes Mellitus (TB) and Tuberculosis (TB) were associated with prolonged hospitalization, we also found that delirium superimposed on cardiovascular and infectious diseases was significantly associated with longer duration of hospital stay. While delirium itself has been consistently reported to be an independent predictor for increased length of hospital stay [12] [13] [14], some medical conditions such as complicated TB, complicated DM and stroke often require longer duration of hospitalization due to severity of the illness or nature of the treatment. In support of this we found that patients on antikocks and oral hypoglycaemia/insulin had a longer duration of hospital stay.

This study however found no significant association between respondents' demographic characteristics and length of hospital stay. This is in keeping with the results of some previous studies that found delirium to be an independent predictor of hospital outcomes including length of stay, even after controlling for baseline patient's characteristics like age and gender among others [10] [13].

\section{Strengths and Limitations of the Study}

With the paucity of literature on the clinical outcomes of delirium in Nigeria, this study is one of the few, if any, to determine the length of hospital stay in 
medical inpatients with and without delirium, and the fact that the sample had representation from a wide range of medical conditions, with participants drawn from both rural and urban areas of North-Central Nigeria, allows for generalization of findings among medically-ill adults in this region. The study however had some limitations that also need to be acknowledged. In the first place, the current findings cannot be generalized across populations in Nigeria, rather limited to medically-ill adults in a tertiary hospital in North-Central Nigeria, until further studies have replicated similar findings in other regions of Nigeria. Additionally, we narrowed our findings to Hospital length of stay, while other clinical outcomes such as mortality and other complications may also be common. Furthermore delirium was measured in medically-ill patients admitted through A and $\mathrm{E}$ unit of the hospital within 24 hours of admission only. It is possible for other patients to develop delirium after 24 hours and still be followed up for length of stay as non delirious patients.

\section{Conclusion/Recommendation}

This study concludes that delirium is highly prevalent among medical inpatients in Nigeria, with length of hospital stay significantly increased among respondents with delirium compared to those without. It also highlights some clinical characteristics such as current medication use, late hospital presentation and type of diagnosis that were particularly associated with prolonged hospitalization among those with delirium.

It is recommended that an effective model for regular health education aimed at promoting health seeking attitude, environmental sanitation as well as healthy lifestyles needs to be developed. In addition, there should be continuous medical education for health workers, especially those in primary and secondary health institutions, aimed at early risk identification, diagnosis and treatment, as well as early referral of medically-ill patients who require tertiary level of care.

\section{Acknowledgements}

The authors wish to thank the Resident Doctors of the Jos University_Teaching Hospital (JUTH) who assisted with data collection. We wish to thank the heads of $A \& E$ and Internal medicine for granting us the permission to use their units for the study. We would also like to thank the patients and their relatives for their cooperation during the study.

\section{Conflicts of Interest}

The authors declare no conflicts of interest regarding the publication of this paper.

\section{References}

[1] Adamis, D., Treloar, A., Martin, F.C. and Macdonald, A.J. (2007) A Brief Review of the History of Delirium as a Mental Disorder. History of Psychiatry, 4, 459-469. 
https://doi.org/10.1177/0957154X07076467

[2] Rockwood, K. and Lindesay, J. (2002) The Concept of Delirium: Historical Antecedents and Present Meanings. In: Lindesay, J., Rockwood, K. and Macdonald, A., Ed., Delirium in Old Age, Oxford University Press, 1-8.

[3] Jaspers, K. (1963) Manchester: General Psychopathology. Manchester University Press, 922.

[4] Lipowski, Z.J. (1991) Delirium: How Its Concept Has Developed. International Psychogeriatrics, 2, 115-120. https://doi.org/10.1017/S1041610291000595

[5] American Psychiatric Association (1980) Diagnostic and Statistical Manual of Mental Disorders. 3rd Edition, American Psychiatric Association, Washington DC.

[6] American Psychiatric Association (2013) Diagnostic and Statistical Manual of Mental Disorders. 5th Edition, American Psychiatric Association, Washington DC.

[7] Han, J.H., Zimmerman, E.E., Cutler, N., Schnelle, J., Morandi, A., Dittus, R.S., Storrow, A.B. and Ely, E.W. (2009) Delirium in Older Emergency Department Patients: Recognition, Risk Factors, and Psychomotor Subtypes. Academic Emergency Medicine, 16, 193-200. https://doi.org/10.1111/j.1553-2712.2008.00339.x

[8] Ajiboye, P.O. and Adelekan, M.L. (2004) A Prospective Analysis of In-Patient Consultation Liason Psychiatry in a Nigeria Teaching Hospital. East African Medical Journal, 81, 620-625.

[9] Han, J.H., Eden, S., Shintani, A., Morandi, A., Schnelle, J., Dittus, R.S., Storrow, A.B. and Ely, E.W. (2011) Delirium in Older Emergency Department Patients Is an Independent Predictor of Hospital Length of Stay. Academic Emergency Medicine, 18, 451-457. https://doi.org/10.1111/j.1553-2712.2011.01065.x

[10] Inuoye, S.K., Rushing, J.T., Foreman, M.D., Palmer, R.M. and Pompei P. (1998) Does Delirium Contribute to Poor Hospital Outcomes? A Three Site Epidemiologic Study. Journal of General Internal Medicine, 13, 234-242.

https://doi.org/10.1046/j.1525-1497.1998.00073.x

[11] Fick, D.M., Steis, M.R., Waller, J.L. and Inuoye, S.K. (2013) Delirium Superimposed on Dementia Is Associated with Prolonged Length of Stay and Poor Outcomes in Hospitalized Older Adults. Journal of Hospital Medicine, 8, 500-505. https://doi.org/10.1002/jhm.2077

[12] Siddiqi, N., House, A.O. and Holmes, J.D. (2006) Occurrence and Outcome of Delirium in Medical Inpatients: A Systematic Literature Review. Age Ageing, 35, 350-364. https://doi.org/10.1093/ageing/afl005

[13] Mariz, J., Santos, S.C. and Afonso, H. (2013) Risk and Clinical Outcome Indicators of Delirium in an Emergency Department Intermediate Care Unit (EDIMCU): An Observational Prospective Study. BMC Emergency Medicine, 13, 2-8. https://doi.org/10.1186/1471-227X-13-2

[14] Zhang, Z., Pan, L. and Ni, H. (2013) Impact of Delirium on Clinical Outcomes in Critically Ill Patients: A Meta-Analysis. General Hospital Psychiatry, 35, 105-111. https://doi.org/10.1016/j.genhosppsych.2012.11.003

[15] Paddick, S.M., Gray, W.K., Dotchin, C., Kisoli, A., Mbowe, G., Kisima, J., Lwezaula, F., Mkenda, S,. Mushin, D., Teodorczuk, A., Ogunniyi, A. and Walker, R. (2015) Prevalence of Deliriun in Older Hospitalized Adults in Tanzania. The Identification and Interventions for Dementia in Elderly African Study, 86, 9.

[16] Leslie, D.L., Marcantonio, E.R., Zhang, Y., Leo-Summers, L. and Inouye, S.K. (2008) One-Year Health Care Costs Associated with Delirium in the Elderly Population. Arch Internal Medicine, 168, 27-32. https://doi.org/10.1001/archinternmed.2007.4 
[17] O'Keeffe, S. and Lavan, J. (1997) The Prognostic Significance of Delirium in Older Hospital Patients. Journal of the American Geriatrics Society, 45, 174-178. https://doi.org/10.1111/j.1532-5415.1997.tb04503.x

[18] Thomason, J.W., Shintani, A., Peterson, J.F., Pun, B.T., Jackson, J.C. and Ely, E.W. (2005) Intensive Care Unit Delirium Is an Independent Predictor of Longer Hospital Stay: A Prospective Analysis of 261 Non-Ventilated Patients. Critical Care, 9, 375-381. https://doi.org/10.1186/cc3729

[19] McCusker, J., Cole, M.G., Dendukuri, N. and Belzile, E. (2003) Does Delirium Increase Hospitals Stay? Journal of American Geriatrics Society, 51, 539-1546.

[20] Kish, L. (1965) Survey Sampling. John Whilley and Sons, New York.

[21] Mekonen, T., Mihretie, G., Assefa, D., Fekadu, W. and Mehretie, Y. (2015) Magnitude and Associated Factors of Delirium among Hospitalized Patients, Ethiopia: A Cross Sectional Study. Journal of Psychiatry, 18, 267.

[22] Adamis, D., Martin, F.C., Treloar, A. and Macdonald, A.J. (2005) Capacity, Consent and Selection Bias in a Study of Delirium. Journal of Medical Ethics, 3, 137-143. https://doi.org/10.1136/jme.2002.000919

[23] Vanpee, D., Gillet, J.B. and Dupuis, M. (2004) Clinical Trials in an Emergency Setting: Implications from the Fifth Version of the Declaration of Helsinki. Journal of Emergency Medicine, 26, 127-131. https://doi.org/10.1016/j.jemermed.2003.04.007

[24] Ola, B.A., Crabb, J., Krishnadas, R., Erinfolami, A.R. and Olagunju, A. (2010) Incidence and Correlates of Delirium in a West African Mental Health Clinic. General Hospital Psychiatry, 32, 176-181. https://doi.org/10.1016/j.genhosppsych.2009.10.005

[25] Ryan, D.J., O’Regan, N.A., Caoimh, R.O., Clare, J., O’Connor, M., Leonard, M., McFarland, J., Tighe, S., O’Sullivan, K., Trzepacz, P.T., Meagher, D. and Timmons, S. (2013) Delirium in an Adult Acute Hospital Population: Predictors, Prevalence and Detection. BMJ Open, 7, pii: e001772. https://doi.org/10.1136/bmjopen-2012-001772

[26] Iseli, R.K., Brand, C., Telford, M. and Logiudice, D. (2007) Delirium in Elderly General Medical Inpatients: A Prospective Study. Internal Medicine Journal, 37, 806-811. https://doi.org/10.1111/j.1445-5994.2007.01386.x

[27] Philippe, V., Sylvie, R., Lise, D. and Pierre-Hugues (2011) Factors Associated with Delirium Severity among Older Persons with Dementia. Journal of Neuroscience Nursing, 43, 62-69. https://doi.org/10.1097/JNN.0b013e31820b5fb6

[28] Cole, M.G., Ciampi, A., Belzile, E. and Zhong, L. (2009) Persistent Delirium in Older Hospitalized Patients: A Systematic Review of Frequency and Prognosis. Age Ageing, 38, 19-26. https://doi.org/10.1093/ageing/afn253

[29] Chukwuezi, C.O. and Anelechi, A.B. (2009) Factors Associated with Delay in Seeking Medical Care among Educated Nigerians. Asian Journal of Medical Sciences, 1, 30-32.

[30] Olasheni, A.S., Kayode, O.O., Oluwaseun, O.A., Taiwo, A.O. and Folashayo, I.A. (2017) What Factors Influence the Average Length of Stay among Stroke Patients in a Nigerian Tertiary Hospital? Pan African Medical Journal, 26, 228.

[31] Alkali, N.H., Bwala, S.A., Akano, A.O., Osi-Ogbu, O., Alabi, P. and Ayeni, O.A. (2013) Stroke Risk Factors, Subtypes, and 30-Day Case Fatality in Abuja, Nigeria. Nigerian Medical Journal: Journal of the Nigeria Medical Association, 54, 129. http://www.nigeriamedj.com/text.asp?2013/54/2/129/110051 https://doi.org/10.4103/0300-1652.110051 
[32] Oladimeji, O., Isaakidis, P., Obasanya, O.J., Eltayeb, O., Khogali, M., Van den Bergh, R., Kumar, A.M.V., Hinderaker, S.G., Abdurrahman, S.A., Lawson, L. and Cuevas, L.E. (2014) Intensive-Phase Treatment Outcomes among Hospitalized Multidrug-Resistant Tuberculosis Patients: Results from a Nationwide Cohort in Nigeria. PLoS ONE, 9, e94393. https://doi.org/10.1371/journal.pone.0094393

[33] Ajayi, E.A. and Ajayi, A.O. (2009) Pattern and Outcome of Diabetic Admissions at a Federal Medical Center: A 5-Year Review. Annals of African Medicine, 8, 271-275. http://www.annalsafrmed.org/text.asp?2009/8/4/271/59584 https://doi.org/10.4103/1596-3519.59584

[34] Ogbera, A.O., Chinenye, S., Onyekwere, A. and Fasanmade, O. (2007) Prognostic Indices of Diabetes Mortality. Ethnicity \& Disease, 17, 721-725.

[35] Koton, S., Bornstein, N., Tsabari, R. and Tanne, D. (2010) Investigators N. Derivation and Validation of the Prolonged Length of Stay Score in Acute Stroke Patients. Neurology, 74, 1511-1516. https://doi.org/10.1212/WNL.0b013e3181dd4dc5

[36] Krop, J.S., Powe, N.R., Weller, W.E., Shaffer, T.J., Saudek, C.D. and Anderson, G.F. (1998) Patterns of Expenditures and Use of Services among Older Adults with Diabetes. Implications for the Transition to Capitated Managed Care. Diabetes Care 21, 747-752. https://doi.org/10.2337/diacare.21.5.747 


\section{Appendix}

\section{1: Sociodemographic Questionnaire \\ Section A \\ Socio-Demographic Data}

1.Study serial number:

2.Hospital number:

3. Residential address:

4. Age in years:

5.Gender: (a) Male ( ) (b) Female ( )

6.Ethnicity:

7. Occupation: (a) Student ( ) (b) Civil Servant ( ) (c) Trader ( ) (d) Farmer ( ) (e) others, please specify.

8. Marital status single: Single ( ) Married ( ) Divorced ( ) Widowed ( )

9. Educational qualification: (tick as appropriate):

Primary ( ) Secondary ( ) Tertiary ( ) None ( ) Postgraduate ( )

10. Religion: (a) Christian ( ) (b) Muslim ( ) (c) Traditional ( ) (d) Others please specify.....

11. Average Monthly income (including that of your spouse)

a) Below 20,000 Naira ( )

b) 20,000 - 50,000 Naira ( )

c) Above 50,000 Naira ( )

\section{Section B}

Medical and psychiatric history:

1.Please indicate if you have any of the following conditions:

a.Diabetes mellitus ( ) b. hypertension ( ) c. HIV d. seizure disorder ( ) e. Mental illness ( ) f. others specify

2.Duration of current symptoms? (a) 0 - 2 weeks ( ) (b) $2-4$ weeks ( ) (c) Above 4 weeks ( )

3. Have you ever been diagnosed with mental illness? Yes ( ) No ( )

If Yes, (a) Treated ( ) (b) Not treated ( ) (c) Still on treatment ( ).

4. Do you use Alcohol or other drugs of abuse? (a) Yes ( ) (b) No ( ) (c) Stopped ( ).

If Yes

i) Duration

ii) Amount

iii) Frequency.

iv) Last intake...

5. Have you been having difficulties with your memory or intellectual functioning? Yes( ) $\mathrm{No}($ )

If Yes, (a) Areas of activities affected ( ) (b) Areas of activities not affected ()

Section C

To be completed by the researcher

Current Medical Diagnosis. 
Length of stay in hospital (in days).....

Episodes of injury to self or others during period of stay in hospital.

Type of Medications used.

Table A1. Level of consciousness: RASS (Richmond Agitation Sedation Scale).

\begin{tabular}{ccc}
\hline Scale & Label & Description \\
\hline+4 & Combative & Combative, violent, immediate danger to staff \\
+3 & Very agitated & Pulls to remove tubes or catheters; aggressive \\
+2 & Agitated & Frequent non-purposeful movement, fights ventilator \\
0 & Restless & Anxious, apprehensive, movement, not aggressive \\
-1 & Alert and calm & Spontaneously pays attention to caregiver \\
-2 & Drowsy & Not fully alert, but has sustained awakening to voice \\
-3 & Light sedation & (eye opening and contact $>10$ sec)
\end{tabular}

If RASS is $\geq-3$ proceed to CAM (is patient CAM positive or negative?)

\begin{tabular}{ccc}
-4 & Deep sedation & $\begin{array}{c}\text { No response to voice, but } \\
\text { movement or eye opening to } \\
\text { physical stimulation }\end{array}$ \\
-5 & Unarousable & $\begin{array}{c}\text { No response to voice or physical } \\
\text { stimulation }\end{array}$ \\
\hline
\end{tabular}

If RASS is -4 or -5 Stop (patient unconscious), RECHECK later.

Table A2. Confusion assessment method (CAM).

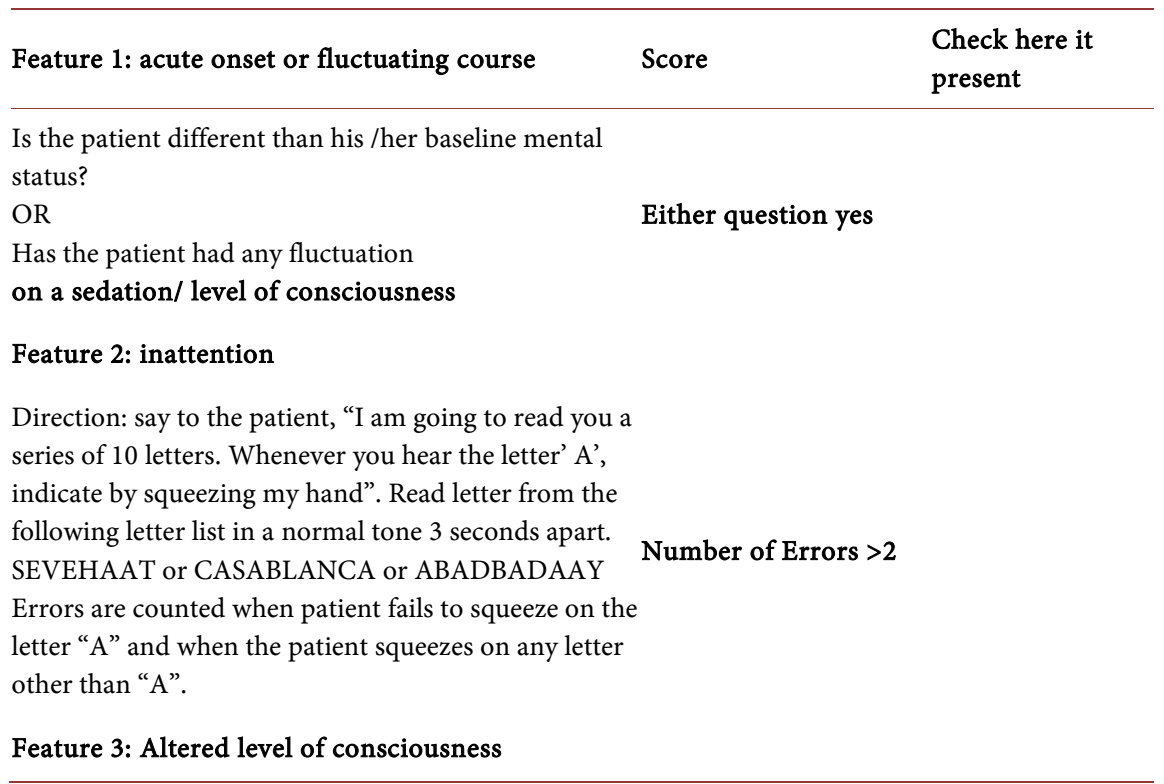




\section{Continued}

Present if the actual RASS score is anything other

RASS anything other

than alert and calm (zero)

than zero

Feature 4: Disorganized thinking

Yes/No questions:

1) Will a stone float on water?

2) Are there fish in the sea?

3) Does one pound weigh more than two Pounds?

4) Can you use a hammer to pound a nail?

Errors are counted when the patient incorrectly answers a question.

Command:

Combined number of

Say to patient: "Hold up this many fingers" (Hold 2

fingers in front of patient)

"Now do the same thing with the other hand" (Do not repeat number of fingers) ${ }^{\star}$ If the patient is unable to move both arms, for $2^{\text {nd }}$ part of command ask patient to "Add one more finger"

An error is counted if patient is unable to complete the entire command.

\begin{tabular}{|c|c|c|}
\hline Overall CAM & Criteria Met & $\begin{array}{c}\text { CAM Positive } \\
\text { (Delirium Present) }\end{array}$ \\
\hline Feature 1 plus 2 and either 3 or 4 present $=$ CAM & & CAM \\
\hline positive & Criteria Not Met & $\begin{array}{c}\text { Negative } \\
\text { (No Delirium) }\end{array}$ \\
\hline
\end{tabular}

